\title{
The Relationship Between the Yo-Yo Tests, Anaerobic Performance and Aerobic Performance in Young Soccer Players
}

\author{
by

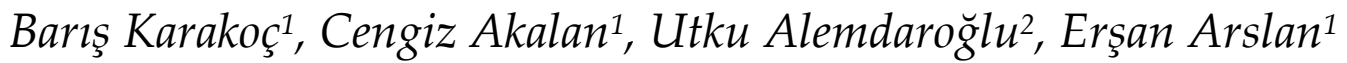

\begin{abstract}
The purposes of this study were to determine the relationship between performance in the Yo-Yo intermittent recovery test level 1 (YIRT1), the Yo-Yo intermittent recovery test level 2 (YIRT2) and the Yo-Yo endurance test (continuous) (YET) with maximal oxygen uptake (VOzmax) and Wingate anaerobic performance (WaNT) test results in young soccer players (age $15.00 \pm 0.0$ years, body height $176.3 \pm 4.2 \mathrm{~cm}$ and body mass $68.1 \pm 3.6 \mathrm{~kg}$ ). An ergospirometry device was used during the treadmill test (TRT) to determine VOzmax. At the end of the study, significant differences were found between the Yo-Yo tests and TRT in terms of HRmax $(T R T=195,92, Y I R T 1=$ $197,83$, YIRT2 $=198,5 Y E T=198)(p>0.05)$. While there were moderate correlations between VO2max and YIRT 1-2 performances (respectively, $r=0.56, r=0.53$ ), there was only a weak relationship between $V O_{2}$ max and YET performance $(r=0.43$ ) (distance covered). There were also moderate significant negative correlations between performance in the YIRT2 and peak power measured in the WaNT $(r=-0.55)$, although there were no significant correlations between performance in the three tests and average power. A moderate negative correlation was found between performance in the YIRT2 and Fatigue index (FI) $(r=-0,66)$. In conclusion, the YIRT2 may be a more suitable field test for determining both aerobic and anaerobic performance in soccer players.
\end{abstract}

Key Words: Yo-Yo Tests, Wingate test, VOzmax, soccer, anaerobic power

\section{Introduction}

Soccer performance is not only affected by technical skills, a player's physical capacity is known to exert a major influence on his match performance (Little and Williams, 2007). The activities involved in soccer are of intermittent nature, with changes every 3-5 s, resulting in repeated high-intensity spells of play (Krustrup et al., 2006; Little and Williams, 2007). A soccer game involves jumping, shooting, challenges, turns, dribbles, sprints, controlling the ball under pressure, running at different speeds, and sliding tackles; both aerobic and anaerobic energetic pathways are used during games (Açıkada et al., 1998; Stolen et al., 2005). The recovery capacity of players during repeated high-intensity bouts is closely related to the development of aerobic capacity (Tomlin and Wenger, 2001; Castagna et al., 2008). Moreover, players' high intensity movements are positively associated with their anaerobic energy pathways (Castagna et al., 2006). The outcome of a match may be determined by the aerobic and anaerobic capacity of players and it is therefore important to evaluate their aerobic and anaerobic capacity (Bangsbo et al., 2008).

The assessment of physical capacities of athletes is one of the most important issues in modern sports. Coaches and sport scientists use field and laboratory tests for screening candidates, in selection procedures, or to monitor the efficacy of training regimes (Norkowski, 2002). Numerous field tests have been developed to assess the physical capacities of athletes. Yo-Yo tests have rapidly become one of the most extensively studied shuttle run tests in sports science, due to their specificity and practicality (Krustup et al., 2003). These tests have also been applied to assess

1 - Ankara University, School of Physical Education and Sports, Ankara, TURKEY.

2 - Pamukkale University Schools of Sport Sciences and Technology, Denizli, TURKEY.

Authors submitted their contribution of the article to the editorial board.

Accepted for printing in Journal of Human Kinetics vol. 35/2012 on December 2012. 
players' abilities to repeatedly perform highintensity exercise (Bangsbo et al., 2008) in many team sports such as soccer (Krustup et al., 2003; Aziz et al., 2005), basketball (Castanga et al., 2006) and rugby (Atkins, 2005) and it is thought that YoYo tests are one of most effective field-based means of assessing soccer player's endurance performance (Aziz et al., 2005).

Many studies have examined the relationship between Yo-Yo tests performance and $\mathrm{VO}_{2}$ max using an oxygen analyzer, but the results of these studies present a scattered picture (Bangsbo et al., 2008). While some studies have found only weak correlation between $\mathrm{VO}_{2}$ max and Yo-Yo test performance (Aziz et al., 2005; Castagna et al., 2006), other studies have shown a moderate to strong correlation (Krustrup et al., 2003; Thomas et al., 2006).

Few studies have examined the relationship between Yo-Yo test performance and anaerobic fitness. Castagna et al. (2006) found no correlation between counter movement jump and Yo-Yo Endurance Test (YET) or Yo-Yo Intermittent Recovery Test Level 1 (YIRT1) performance. Similarly, Krustrup et al. (2006) found no relationship between Yo-Yo Intermittent Recovery Test Level 2 (YIRTL2) and repeated sprint performance. The most commonly used test of anaerobic fitness is the Wingate anaerobic test (WaNT), which is a laboratory based cycle ergometer test (Hoffman et al., 2000). However, no previous study has compared Yo-Yo tests performance with WaNT performance, nor have any studies examined the relationships between the results of different Yo-Yo tests. It is thought that one of the Yo-Yo tests may meet the requirements of simultaneous stimulation of the aerobic and anaerobic energy system (Krustrup et al., 2006; Bangsbo, 1994). Therefore, the objectives of the current study were threefold a) to determine the relationship between performances in YIRT1, YIRT2 and YET and $\mathrm{VO}_{2}$ max, b) to determine the relationship between Yo-Yo test and WaNT test results, c) to examine the differences in heart rate responses to Yo-Yo tests and TRT in young soccer players.

\section{Material and Methods}

\section{Subjects}

Twelve soccer players voluntarily participated in the study. The mean measurements gathered were as follows: age 15.00 \pm 0.0 years, body height $176.3 \pm 4.2 \mathrm{~cm}$ and body mass $68.1 \pm 3.6 \mathrm{~kg}$. The subjects were informed about the possible risks and benefits of the study and gave their informed consent to participate in this study, which was approved by the Clinical Research Ethical Committee of Ankara University. The study was conducted over a 2-week period, during which the players did not participate in any other training or matches. All players were recruited from the same team and had been playing competitively for at least two years. They were familiarized with the tests' protocols and had undergone the YIRT1, YIRT2, YET, TRT and WaNT at least once prior to the study.

\section{Procedures}

The five test trials were conducted as separate sessions with 2-day intervals between tests. On day 1, body composition measurements were taken and the participants completed a test session on a treadmill (Cosmed, Gambettola, Italy) to determine maximal oxygen uptake ( $\left.\mathrm{VO}_{2} \mathrm{max}\right)$; on day 2, the participants completed a battery of tests that examined anaerobic physical performance (WaNT); on days 3, 4, 5 the YIRT1, YIRT2 and YET were performed randomly. The YIRT1, YIRT2, YET trials were conducted on the same facilities (synthetic pitch) and all tests were performed between 10:30 and 12:30. Before the players undertook the tests they were instructed to exert maximal effort and were verbally encouraged to run for as long as possible. The standardized warm-up for the YIRT1, YIRT2 and YET trials consisted of 3 minutes of running the $20 \mathrm{~m}$ distance back and forth at a set pace (i.e. 8.0 $\mathrm{km} / \mathrm{h}$ ) with the help of "beep" sounds; for the TRT trials, it consisted of 3 minutes of running on a treadmill at $8 \mathrm{~km} / \mathrm{h}$. This was followed by 5 minutes of stretching, focusing on the lower limb muscles (Aziz et al., 2005). During the TRT, expired gases were analyzed using a breath-bybreath automated gas-analysis system (Fitmate Pro; Cosmed, Italy). The flow, volume, and gas analyzer were calibrated before each player's test according to the manufacturer's instructions. Heart rate data were stored using HR monitors (Polar Electro OY, Kempele, Finland) throughout the tests. The stored data were transferred to computer and filtered by Polar Precision Performance Software ${ }^{\mathrm{TM}}$ (PPP4, Finland). The highest HR measurement was recorded as 
HRmax. The temperature and relative humidity at the test site were consistent throughout the study, ranging between 25.4-27.6 ${ }^{\circ} \mathrm{C}$ and 51.3-53.7\%, respectively. Each player completed all of the tests within the two-week period.

\section{Maximal Oxygen Uptake (TRT)}

The treadmill exercise testing was performed to voluntary exhaustion on a motorized treadmill (Cosmed, Gambettola, Italy). All tests were performed under standardized conditions in a stable laboratory environment. Each player warmed-up on the treadmill (Venus, HPCosmos, Germany) for $3 \mathrm{~min}$ at $8.0 \mathrm{~km} \cdot \mathrm{h}^{-1}$ and followed this with $5 \mathrm{~min}$ of stretching the lower limbs (Aziz et al., 2005). For each subject, the test commenced with three minutes of running at 8.0 $\mathrm{km} \cdot \mathrm{h}^{-1}$ at zero gradient, followed by speed increases of $2 \mathrm{~km} \cdot \mathrm{h}^{-1}$ for the next 2 minutes. Thereafter, gradient was systematically increased by $2 \%$ every minute until a maximum of $12 \%$ was attained. If termination was not achieved by this time, then increases of $1 \mathrm{~km} \cdot \mathrm{h}^{-1}$ for each following 1-minute stage until exhaustion. This procedure was used by Aziz et al. (2005) in a similar study.

\section{The Wingate Anaerobic Test (WAnT)}

The Wingate Anaerobic Test (WAnT) was conducted using a mechanically braked cycle ergometer (834 E, Monark, Vansbro, Sweden). The WAnT test was administered for 30 seconds. The subjects warmed up for 5 minutes at a pedaling rate of $50 \mathrm{rpm}$ against no load, after which they rested for $5 \mathrm{~min}$. They were then instructed to pedal as fast as they could. When the pedaling rate reached approximately $160-170 \mathrm{rpm}$, the resistance was applied and subjects continued pedaling as fast as possible for $30 \mathrm{~s}$. Subjects were verbally encouraged during the test. Peak power and mean power was calculated automatically by the Wingate Anaerobic Test computer program (Kin-işler et al., 2008; Inbar et al., 1996). A fatigue index (FI) was calculated by using the following equation (Inbar et al., 1996).

\section{Equation 1}

FI $=[($ Peak Power Output - Min Power Output $) /$ Peak Power Output] x 100

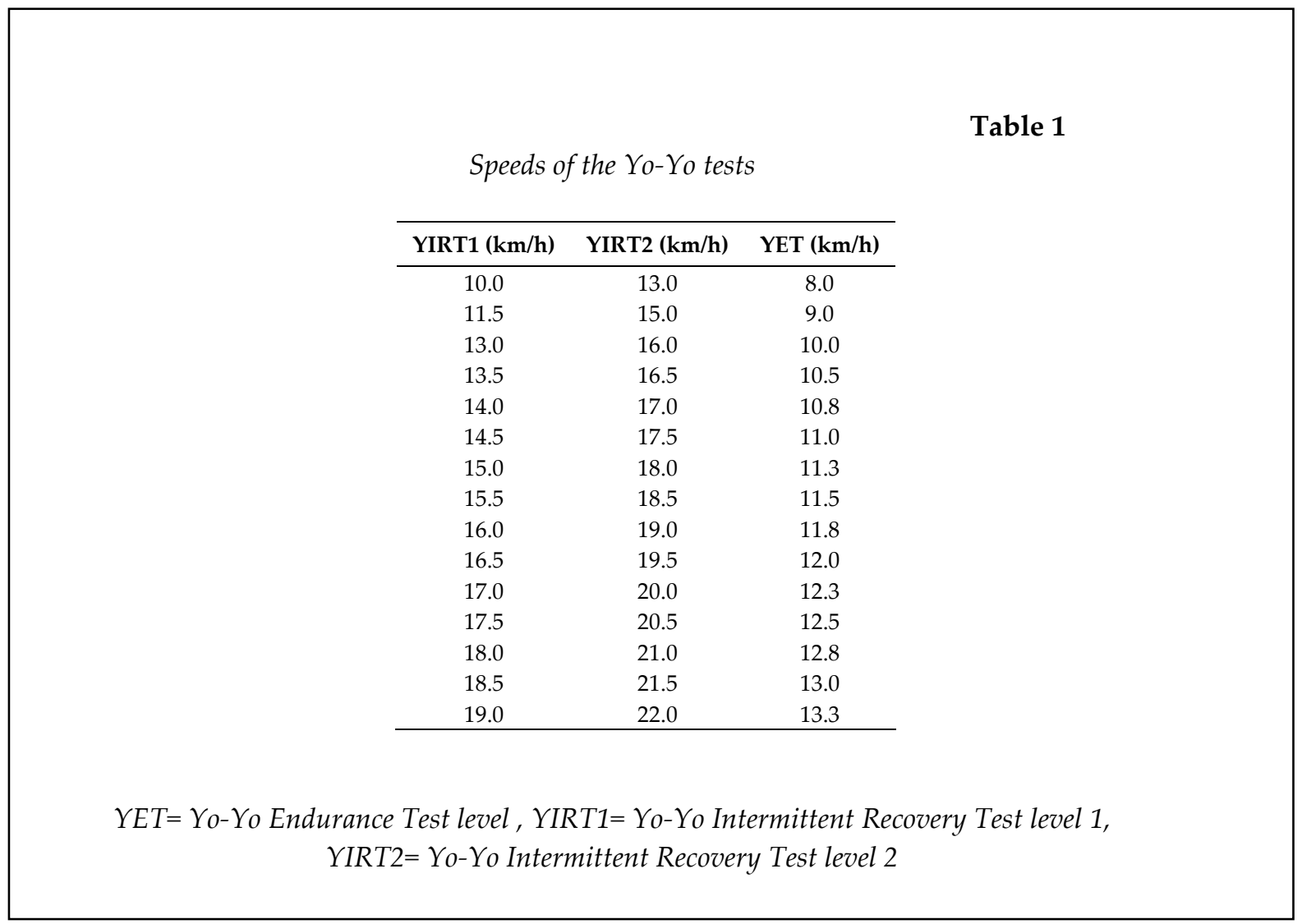




\section{The Yo-Yo intermittent recovery tests (YIRT1-} YIRT2)

Both YIRT1 and YIRT2 consist of repeated 20-m runs back and forth between the starting, turning, and finishing lines at a progressively increased speed, which is controlled by audio beeps from a tape recorder. When the subjects failed twice to reach the finishing line in time, the distance covered was recorded as the test result (Krustrup et al., 2003; Bangsbo, 1994). YIRT 1 has 4 running bouts at $10-13 \mathrm{~km} \cdot \mathrm{h}^{-1}$ and another 7 runs at $13.5-14 \mathrm{~km} \cdot \mathrm{h}^{-1}$, whereafter it continues with stepwise $0.5 \mathrm{~km} \cdot \mathrm{h}^{-1}$ speed increments after every 8 running bouts (i.e., after 760, 1080, 1400, $1720 \mathrm{~m}$, etc.) until exhaustion (Krustrup et al., 2003). YIRT 2 test started at a speed of $13 \mathrm{~km} \cdot \mathrm{h}^{-1}$, which increased by $2 \mathrm{~km} \cdot \mathrm{h}^{-1}$ after the first stage and by $1 \mathrm{~km} \cdot \mathrm{h}^{-1}$ after the second stage, afterwards it continued with stepwise $0.5 \mathrm{~km} \cdot \mathrm{h}^{-1}$ speed increments after every stage until exhaustion (Krustrup et al., 2003).

\section{The Yo-Yo endurance test level (YET)}

The Yo-Yo Endurance Test level (continuous) is a variation of the Yo-Yo test series. The YET consists of repeated $2 \times 20 \mathrm{~m}$ runs back and forth between the starting, turning, and finishing line at a progressively increased speed controlled by audio beeps from a tape recorder (Bangsbo, 1994). When the participant stops, the final speed and the number of performed $20 \mathrm{~m}$ distances at this speed are recorded, including the last run.

\section{Statistical Analyses}

The data are reported as means and standard deviations. Before using parametric tests, the assumption of normality was verified using the Shapiro-Wilk test. A one-way repeatedmeasures analysis of variance was performed on heart rate responses in the YET, YIRT 1-2 and TRT. A Bonferroni Post Hoc test was applied to make a pairwise comparison between YET, YIRT
1-2 and TRT tests. The Pearson product moment correlation coefficient ( $r$ ) was used to determine the relationships between Yo-Yo test performance, measured $\mathrm{VO}_{2}$ max in the TRT and anaerobic physical performance. The level of statistical significance was set at $\mathrm{p}<0.05$.

\section{Results}

Table 2 shows the results of YIRT1, YIRT2, YET, TRT and WaNT tests.

Table 3 shows the correlations between performances (in terms of distance covered) in the three tests and the measured $\mathrm{VO}_{2}$ max obtained from TRT and WaNT test performances for the 12 players. There were weak correlations between performance in the YET and $\mathrm{VO}_{2}$ max, whereas moderate correlations were found between performance in the YIRT1, the YIRT2 and $\mathrm{VO}_{2} \max$ obtained in the TRT. Moreover, there were moderate significant correlations between performance in the YIRT2 and peak power obtained in the WaNT. In contrast, there were no significant correlations between performance in any of the three tests and average power obtained in the WaNT. Finally, there were moderate negative correlations between performance in the YIRT2 and FI, whereas no correlations were found between performance in the YIRT1 or the YET and FI.

Table 4 shows the correlations between performances (in terms of distance covered) in the Yo-Yo tests for the 12 players. No correlations were found between performance in the YET, in the YIRT1 and in the YIRT2.

Figure 1 shows the heart rate responses measured during the YET, YIRT1-2 and TRT for the 12 players. TRT HRmax values are significantly different from YIRT1-2 and YET HRmax values $(p<0.05)$

\begin{tabular}{|lccccc|}
\hline \multicolumn{5}{c|}{ Table 2 } \\
\hline \multicolumn{7}{c}{ The results of tests } \\
$\begin{array}{llllll}\text { VO2max } \\
(\mathrm{ml} / \mathrm{kg} / \mathrm{min})\end{array}$ & $\begin{array}{c}\text { YIRT 1 Distance } \\
(\mathrm{m})\end{array}$ & $\begin{array}{c}\text { YIRT 2 Distance } \\
(\mathrm{m})\end{array}$ & $\begin{array}{c}\text { YET Distance } \\
(\mathrm{m})\end{array}$ & $\begin{array}{c}\text { WaNT peak } \\
\text { power (watt) }\end{array}$ & $\begin{array}{c}\text { Want } \\
\text { average } \\
\text { power (watt) }\end{array}$ \\
\hline $59.95 \pm 1.23$ & $2730.75 \pm 159.38$ & $1208.33 \pm 89.22$ & $2086.67 \pm 128.30$ & $719.12 \pm 79.20$ & $550.93 \pm 37.06$ \\
\hline
\end{tabular}


Table 3

Correlations between measured vormax, WaNT test performance and Yo-Yo tests distances

\begin{tabular}{lcccc}
\hline & $\begin{array}{c}\mathrm{VO}_{2 m a x} \\
\left(\mathrm{ml} \cdot \mathrm{kg}^{-1} \cdot \mathrm{min}^{-1}\right)\end{array}$ & $\begin{array}{c}\text { Average Power } \\
(\text { watt })\end{array}$ & $\begin{array}{c}\text { Peak } \\
\text { Power }\end{array}$ & FI \\
\hline YIRT1 Distance (m) & $0.56^{*}$ & 0.27 & -0.04 &,- 39 \\
YIRT2 Distance (m) & $0.53^{*}$ & -0.13 & $-0.55^{*}$ &,$- 66^{*}$ \\
YET Distance (m) & $0.43^{*}$ & 0.17 & 0.05 &,- 12 \\
\hline
\end{tabular}

$V_{2}$ max $=$ Maximal oxygen uptake,; FI= Fatigue index $Y E T=Y_{0}-Y_{O}$ Endurance Test level, YIRT1 $=Y_{0}-Y_{0}$ Intermittent Recovery Test level 1 , $Y I R T 2=Y_{0}-Y_{0}$ Intermittent Recovery Test level $2^{*} p<0.05$

Table 4

Correlation between performances in respective Yo-Yo tests

\begin{tabular}{lcc}
\hline & $\begin{array}{c}\text { YIRT2 Distance } \\
(\mathrm{m})\end{array}$ & $\begin{array}{c}\text { YET Distance } \\
(\mathrm{m})\end{array}$ \\
\hline YIRT1 Distance $(\mathrm{m})$ &, 52 &, 48 \\
YIRT2 Distance $(\mathrm{m})$ & &, 27
\end{tabular}

$Y E T=Y_{0}-Y_{0}$ Endurance Test level, YIRT1 $=Y_{0}$-Yo Intermittent Recovery Test level 1, $Y I R T 2=Y_{0}-Y_{O}$ Intermittent Recovery Test level $2 * p<0.05$

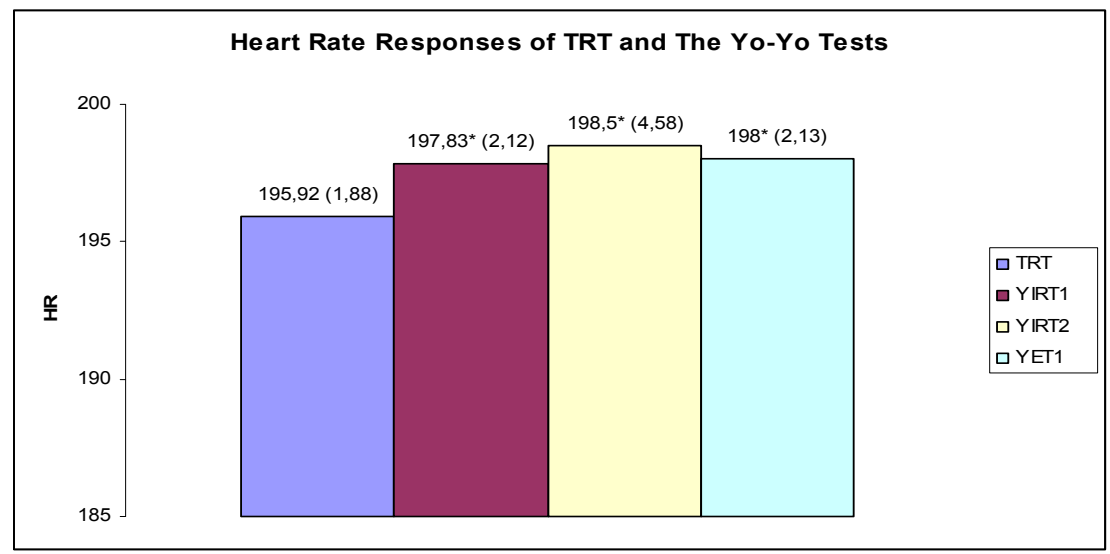

Figure 1

Heart rate responses of TRT and the Yo-Yo tests

*significantly different from the TRT, $p<0.05$; HRmax = Maximal heart rate.

$Y E T=Y_{0}-Y_{0}$ Endurance Test level 1, YIRT1 $=Y_{0}-Y_{0}$ Intermittent Recovery Test level 1, YIRT2 $=Y_{0}$-Yo Intermittent Recovery Test level 2, TRT $=$ Treadmill test 


\section{Discussion}

The measurement of $\mathrm{VO}_{2}$ max using gas and ventilation analysers requires expensive exercise ergometers, laboratory conditions, and trained personnel, not to mention medical staff in attendance (Leibetseder et al., 2002; Stickland et al., 2003), so it may not be appropriate for team sports where testing every player will take time away from training (Stickland et al., 2003; Aziz et al., 2005). For these reasons, there is increased interest in predictive tests (Aziz et al., 2005) and sports scientists have focused on comparing these tests with each other. The major finding of this study is that, while moderate relationships were found between measured $\mathrm{VO}_{2}$ max and distance covered in the YIRT1 and YIRT2, only a weak correlation was found between distance covered in the YET and measured $\mathrm{VO}_{2}$ max. Krustrup et al. (2003), Thomas et al. (2006) and Rampini et al. (2010) found that YIRT 1 distance correlated strongly with $\mathrm{VO}_{2} \max (\mathrm{r}=.71, \mathrm{r}=.83$, and $\mathrm{r}=0$ .78, respectively). In contrast, only weak correlations were found between distance covered in the YIRT1 and $\mathrm{VO}_{2}$ max by Rampini et al. (2010). However, Castagna et al. (2006) found no correlation between YIRT1 performance and $\mathrm{VO}_{2}$ max. Thus, the relationship between the YIRT1 performance and $\mathrm{VO}_{2}$ max is unclear (Bangsbo et al., 2008).

This study found moderate relationships between measured $\mathrm{VO}_{2}$ max and YIRT2 distance covered. Few studies have previously examined the relationship between YIRT2 performance and $\mathrm{VO}_{2}$ max. While Rampini et al. (2010) found a weak correlation between YIRT2 performance with $\mathrm{VO}_{2} \max$, Krustrup et al. (2006) reported a moderate correlation between YIRT2 performance and measured $\mathrm{VO}_{2} \max$ values $(\mathrm{r}=.56)$. Considering the results of these studies and our own, it seems that the prediction of $\mathrm{VO}_{2}$ max from YIRT1-2 results may not be accurate (Bangsbo et al., 2008).

Another finding of this study is that of a weak correlation between YET performance and measured $\mathrm{VO}_{2}$ max values for the subjects. While no previous study has compared YET performance and $\mathrm{VO}_{2}$ max, the YET is similar to the MST in that they both have a continuous test design, and the results of previous studies examining the relationship between $\mathrm{VO}_{2}$ max and MST performance suggest that the MST provides a valid prediction of $\mathrm{VO}_{2}$ max (Leger and Gadaoury, 1989; Ramsbottom et al., 1988; Aziz et al., 2005). A plausible explanation for the apparently anomalous finding of only a weak correlation between YET and $\mathrm{VO}_{2}$ max could be that these tests operate at different speeds.

One of the important findings of this study is its comparison of HRmax in the YIRT 1-2, the YET and the TRT. Heart rate (HR) monitoring is the most popular indirect method of estimating intensity of exercise and it also seems to be the most practical and low-cost method (Murayama and Ohtsuka, 1999). Previous studies have not generally found differences in terms of HRmax measured during the Yo-Yo tests and in different treadmill tests (Stickland et al., 2003; Aziz et al., 2005; Krustrup et al., 2006; Castagna et al., 2006). Metaxas et al. (2005) also found no significant differences in HRmax values between the Yo-Yo continuous and intermittent tests as well as 2 maximal exercise treadmill tests with continuous and intermittent protocols. In contrast, we found significant differences between HRmax values measured in the TRT and those measured in each of the Yo-Yo tests. This finding is of interest considering that, while the differences between the Yo-Yo intermittent endurance test HRmax and TRT HRmax found by Aziz et al. (2005) were not significant, the TRT HRmax values were still 5 beats per minute lower than the Yo-Yo test HRmax values. These results suggest that the YoYo tests might be more suitable for determining HRmax than the TRT.

The Wingate anaerobic test (WaNT) is the gold standard for evaluating anaerobic capacity. We found moderate relationships between peak power and FI measured in WaNT and YIRT2 performance, which examines the ability to perform repeated high-intensity exercise with a high rate of anaerobic energy turnover (Krustrup et al., 2006). On the other hand, correlations were not found between average power as measured by the WaNT and any of the Yo-Yo tests results in this study. Similarly, Krustrup et al. (2006) did not find correlations between the YIRT2 test results and sprint performance or repeated sprint performance. They also found no correlations between the YIRT2 test results, muscle enzymes, and fiber-type distribution and concluded that no single factor determined a subject's ability to perform this type of exercise. However, Castagna 
et al. (2006) found a significant correlation between YIRTl and vertical jump performance and they reported that performance during highintensity intermittent exercise such as YIRT tests is influenced by maximal muscular power. As can be seen from these conflicting findings, insufficient number of studies have been conducted on relationships between Yo-Yo test and anaerobic performance. Moreover, no previous study has examined correlations between WaNT and Yo-Yo test performance. Thus it seems that further research is needed.

\section{Conclusion}

Our results suggest that Yo-Yo tests could be used interchangeably to determine HRmax. YIRT2 may be more suitable to characterize soccer players' intermittent endurance performance (Aziz et al., 2005) and this test may provide a more effective field-based assessment of both aerobic and anaerobic performance in soccer players.

\section{References}

Açıkada C, Hazır T, Aşçı A, Turnagöl H, Özkara A. Physical and physiological profiles of a second league division soccer team during preparation period. Hacettepe. J Sports Sci Technol, 1998; 1: 3-14

Atkins SJ. Performance of the Yo-Yo intermittent recovery test by elite professional and semi professional rugby league players. J Strength Cond Res, 2005; 19: 222-225

Aziz AR, Tan FHY, Teh KC. Pilot study comparing two field tests with the treadmill run test in soccer players. J Sports Sci Med, 2005; 4: 105-112

Bangsbo J, Iaia M, Krustrup P. The Yo-Yo intermittent recovery test: A useful tool for evaluation of physical performance in intermittent sports. Sports Med, 2008; 38: 37-51

Bangsbo J. Fitness Training in Football: A Scientific Approach. Bagsværd, Denmark: HO Storm, 1-336; 1994

Castagna C, Impellizzeri FM, Rampinini E, D'Ottavio S, Manzi V. The Yo-Yo intermittent recovery test in basketball players. J Sci Med Sport, 2008; 11: 202-208

Castagna C, Impellizzeri FM, Belardinelli R, Abt G, Coutts A, Chamari K, D'Ottavio S. Cardiorespiratory responses to Yo-Yo intermittent endurance test in non-elite youth soccer players. J Strength Cond Res, 2006; 20: 326-330

Castagna C, Impellizzeri FM, Chamari K, Carlomagno D, Rampinini E. Aerobic fitness and Yo-Yo continuous and intermittent tests performances in soccer players: A correlation study. J Strength Cond Res, 2006; 20: 320-325

Castagna C, Abt G, D'Ottavio S. Competitive level differences in Yo-Yo intermittent recovery and twelve minute run test performance in soccer referees. J Strength Cond Res, 2005; 19: 805-809

Hoffman JR, Epstein S, Einbinder M, Weinstein Y. A comparison between the wingate anaerobic power test and both vertical jump and line drill tests in basketball players. J Strength Cond Res, 2000; 14: 261-264

Inbar O, Bar-Or, Skinner J. The Wingate Anaerobic Test. Human Kinetic, Champaign, IL, 41-71; 1996

Kin-İşler A, Arıburun B, Özkan A, Aytar A, Tandogan R. The relationship between anaerobic performance, muscle strength and sprint ability in American football players. Isokinet Exerc Sci, 2008; 16: 87-92

Krustrup P, Mohr M, Nybo L, Jensen JM, Nielsen JJ, Bangsbo J. The Yo-Yo IR2 Test: Physiological response, reliability and application to elite soccer. Med Sci Sport Exer, 2006; 38: 1666-1673

Krustrup P, Mohr M, Amstrup T, Rysgaard T, Johansen J, Steensberg A, Pedersen P, Bangsbo J. The Yo-Yo Intermittent Recovery Test: Physiological response, reliability and validity. Med Sci Sport Exer, 2003; 35: 697- 705

Leger LA, Gadoury C. Validity of the 20 m shuttle run test with 1 min stages to predict VO max in adults. Can J Sport Sci, 1989; 14: 6-21 
Leibetseder V, Ekmekcioglu C, Haber P. Simple running test to estimate VO2max. JEPonline, 2002; 5: 6-13

Little T, Williams AG. Measures of exercise intensity during soccer training drills with professional soccer players. J Strength Cond Res, 2007; 21: 367-371

Metaxas TI, Kouttianos NA, Kouidi EJ, Deligiannis AP. Comparative study of field and laboratory tests for the evaluation of aerobic capacity in soccer players. J Strength Cond Res, 2005; 19: 79-84

Murayama N, Ohtsuka R. Heart rate indicators for assessing physical activity level in the field. Am J Hum Biol, 1999; 11: 647-657

Norkowski H. Anaerobic Power of Handball Players Representing Various Sport Levels. Journal of Human Kinetics, 2002; 7: 43-50

Ramsbottom R, Brewer J, Williams C. A progressive shuttle run test to estimate maximal oxygen uptake. Brit J Sport Med, 1988; 27: 141-144

Rampinini E, Menaspa P, Sassi A, Azzalin A, Carlomagno D, Castagna C, Impellizzeri FM. Physiological determinants of Yo-Yo intermittent recovery tests in male soccer players. Eur J Appl Physiol, 2010; 108: 401-409

Stickland MK, Petersen SR, Bouffard M. Prediction of maximal aerobic power from the 20-m multi-stage shuttle run test. Can J Appl Physiol, 2003; 28: 272-282

Stolen T, Chamari K, Castagna C, Wisløff U. Physiology of soccer. Sports Med, 2005; 35: 501-536

Thomas A, Dawson B, Goodman C. The Yo-Yo Test: reliability and association with a 20-m shuttle run and $\mathrm{VO}_{2}$ max. Int J Sports Physiol Perform, 2006; 1: 137-149

Tomlin DL, Wenger HA. The relationship between aerobic fitness and recovery from high intensity intermittent exercise. Sports Medicine, 2001; 31:1-11

\section{Corresponding author:}

\section{Utku Alemdaroğlu}

Address: Pamukkale University Schools of Sport Sciences and Technology, KINIKLI Kampusu, Denizli/ TURKEY

Phone: +90 2582962905

Fax: +90 2582962941

E-mail : ualemdaroglu@pau.edu.tr; $\underline{\text { utkualemdaroglu@yahoo.com }}$ 